Original article

\title{
Clustering the envenoming of snakebite in India: The district level analysis using Health Management Information System data
}

\author{
Pradeep S. Salve*, Shrikanta Vatavati, Jyoti Hallad \\ Population Research Centre, JSS Institute of Economic Research, Dharwad, Karnataka, 580004, India
}

\section{A R T I C L E I N F O}

\section{Keywords:}

Snakebite

Animal bite and stings

Envenoming

HIMS

India

\begin{abstract}
A B S T R A C T
Aim: The study aims to estimate the prevalence of snakebite and deaths due to animal bites and stings in India. Methods: The study used Health Management Information System data of years 2017-18 and 2018-19.

Results: Results estimated that 2,00,492 and 2,30,950 persons were envenomed due to the snakebites in the respective years 2017-18 and 2018-19 in India. West Bengal (36.6 person), Tamil Nadu (36.6), Goa (34.5), Maharashtra (32.4), Andhra Pradesh (31.7), Odisha (27.1) and Karnataka (20.3) have higher prevalence of snakebites per 100,000 populations during 2017-18. In 2018-19, cases were increased for West Bengal (39.4), Odisha (37.0), Tamil Nadu (36.4), Andhra Pradesh (35.3) and Maharashtra (35.0). The results also highlighted that 9,200 (2017-18) and 8,890 (2018-19) persons are died due to the animal bites and stings in India. Conclusion: Our findings significantly contributes in the policy making at the administrative level including district level, state level and eventually to the nation.
\end{abstract}

\section{Introduction}

World health organization (WHO) has recognized Snakebite as an important public health issue and included it in the list of 'Neglected Tropical Disease' of developing countries. ${ }^{1}$ Globally, the snakebites kill millions of people every year, though the exact number of snakebites is unknown, the estimates show that up to 2.7 million people were envenoming out of 5.4 million people who have snakebites. Around 81,000 to $1,38,000$ people die every year followed by amputations and other permanent disabilities. ${ }^{2}$ The snakebites of venomous snakes can cause paralysis including prevent breathing, bleeding disorders (haemorrhage), irreversible kidney failure and tissue damage which may resulted in permanent disability and limb amputation. Mainly, agricultural workers, herders, fishermen, hunters, children aged 10-14 years and people living in poorly constructed houses in interior areas are vulnerable to snakebite. ${ }^{3}$ The mortality occurring among people aged between 10 and 30 years socioeconomically affects the household and eventually to nation because the loss of economically productive members of society. In particular, pregnant women are extremely vulnerable to the risk of haemorrhage and miscarriage following a venomous snakebite. ${ }^{4}$ The previous studies evidences that only half of the patients reach to health center within $6 \mathrm{~h}$ of a snakebite in many part of South Asia and delay to reach to health facility resulted in $70-80 \%$ of fatalities. $^{5,6}$

Considerably half of the global snakebite deaths happened in India. ${ }^{7}$ There is no official system which gives an exact figures of snakebite casualties every year. The government and researchers are unsure about the numbers which creates the huge gaps for research. The official data of government reported that around 1,123 and 1,008 deaths are occurred during 2013 and 2014 respectively due to snakebite in India. ${ }^{8}$ But at the same time, paper published in international journals estimated that deaths are lies between 45,900 and 50,900 in India every year and nearly $97 \%$ deaths occurred in rural area. The highest snakebite deaths were reported in West Bengal, Uttar Pradesh, Andhra Pradesh, Tamil Nadu, Bihar, and Maharashtra. Generally, snakebite deaths occurred while sleeping (30\%), playing (30\%) and during field/ outdoor activities (28\%). ${ }^{9-11}$ Since complications of snakebite develop rapidly and irreversibly, medical intervention must be prompt and appropriate. ${ }^{12}$ The deaths are primarily attributed to distance of patient to health facility, scarcity of anti-snake venoms, poor health services, traditional treatment, lack of affordable means of transport due to remote inaccessible area, non-availability of medicine or doctor and referral patterns. ${ }^{13-15}$ In fact, majority of patients die before the access of treatment the at health facility and considerable number die posttreatment because of delay in reaching to the health facility. ${ }^{10}$ At the outset, snakebite is an underestimated cause of accidental death in

\footnotetext{
* Corresponding author.

E-mail addresses: pradeep8889@gmail.com, pradeep_salve@biari.brown.edu (P.S. Salve), shrikanta.vatavati@gmail.com (S. Vatavati), jshallad@rediffmail.com (J. Hallad).
} 
India which need to be address to understand the intensity and prevalence of snakebite through every possible mean. Therefore, the attempt has been made first time to explore the nationally available representative data on snakebites in India.

\section{Methods}

The Health Management Information System (HMIS) data source is an established data source for the Reproductive, Maternal, Neonatal and Child Health (RMNCH) indicators in India. The HMIS online portal was launched in 2008 under the National Rural Health Mission (NRHM), flagship healthcare program under the Ministry of Health and Family Welfare, Government of India. ${ }^{16}$ The portal aims for collection and sharing the health information including family planning, immunization, diarrheal diseases, malaria, leprosy, blindness, deaths of all types, and health services data in a timely manner across the country which serve as the evidences for local planning and policy decision making at the national level. Since 2008, the HIMS portal enables in capturing the data from public health institutions including Primary Health Centre, Community Health Centre, Sub-Divisional Hospital and District Hospital in rural and urban areas as well as from private hospitals. The portal is envisaged as a "Single Window" for all information of health and services data for the Government of India.

We have used the HMIS data of years 2017-18 to 2018-19 for estimating the prevalence of snakebites in India. Along with the health services, the HMIS also covers information on population health including two element associated with the snakebite including; 1 ) snakebites cases registered at the government health facilities and 2) mortality attributed to the animal bites and stings in respective health facilities. We have used these two data elements which are nationally representative and available in HMIS portal only. Further, the prevalence of snakebite is estimated based on 100,000 population using the state level projected population of 2016 in India. ${ }^{17}$ However, the information on deaths attributed to the snakebites are not available in the HMIS but we have indirectly tried to illustrate that the major deaths presented in the category of animal bites and stings are attributed to the snakebites. Aforementioned, the death rate is also estimated on the 100,000 population based on 2016 projected population of India. ${ }^{17}$ Additionally, we have mapped the districts-wise prevalence of snakebite in India employing the geographic information system (GIS) methods.

\section{Results}

\subsection{Envenoming due to snakebite}

The prevalence of snakebite and mortality due to animal bites and stings of two consecutive years presented in Table 1 . The results highlighted that 2,00,492 persons were envenomed because of the snakebite in the year 2017-18 and in the consecutive year 2018-19, total 2,30,950 persons had snakebite in India. The state level analysis shows that mostly larger states have higher reporting of snakebites per 100,000 populations, for instance, 36.6 persons reported snakebite in West Bengal per 100,000 populations in $2017-18$, followed by Tamil Nadu (36.6 persons), Goa (34.5 persons), Maharashtra (32.4 persons), Andhra Pradesh (31.7 persons), Odisha (27.1 persons) and Karnataka (20.3 persons). At the same time, the Union Territories (UTs) of India reported the highest snakebites cases in both the years. For instance, Dadra and Nagar Haveli reported 153 persons with snakebites per 100,000 populations in 2017-18 followed by Puducherry (51.5 persons), Daman and Diu (40.6 persons) and Andaman and Nicobar Islands (22.9 persons). In the subsequent year 2018-19, the cases of snakebites are increased per 100,000 populations excluding the Goa and Tamil Nadu state. West Bengal with 39.4 persons per 100,000 is on the top of the largest state of reporting snakebites followed by Odisha (37.0 persons), Tamil Nadu (36.4 persons), Andhra Pradesh (35.3 persons) and
Table 1

Snakebite prevalence rate and deaths due to animal bites and stings in India (per 100000 persons).

\begin{tabular}{|c|c|c|c|c|c|}
\hline $\begin{array}{l}\text { States and } \\
\text { Union } \\
\text { Territories }\end{array}$ & $\begin{array}{l}\text { Snakebite } \\
(2017-18)\end{array}$ & $\begin{array}{l}\text { Snakebite } \\
(2018-19)\end{array}$ & $\begin{array}{l}\text { Death }^{\mathrm{b}} \\
\text { Rate } \\
2017-18\end{array}$ & $\begin{array}{l}\text { Death } \\
\text { Rate } \\
(2018- \\
19)\end{array}$ & $\begin{array}{l}\text { Estimated }^{\mathrm{a}} \\
\text { Population } \\
2016 \text { (in 000) }\end{array}$ \\
\hline $\begin{array}{l}\text { Andhra } \\
\text { Pradesh }\end{array}$ & 31.7 & 35.3 & 0.85 & 0.68 & 53,167 \\
\hline $\begin{array}{l}\text { Arunachal } \\
\text { Pradesh }\end{array}$ & 5.8 & 7.9 & 0.15 & 0.38 & 1,313 \\
\hline Assam & 3.6 & 5.1 & 0.34 & 0.48 & 32,449 \\
\hline Bihar & 5.5 & 5.4 & 0.13 & 0.06 & 103,908 \\
\hline Chhattisgarh & 19.7 & 22.6 & 1.85 & 1.59 & 25,879 \\
\hline Goa & 34.5 & 29.2 & 0.40 & 0.15 & 1,977 \\
\hline Gujarat & 10.7 & 13.9 & 0.67 & 0.60 & 62,825 \\
\hline Haryana & 2.0 & 4.0 & 0.18 & 0.74 & 27,477 \\
\hline $\begin{array}{l}\text { Himachal } \\
\text { Pradesh }\end{array}$ & 14.9 & 25.2 & 1.54 & 1.23 & 7,095 \\
\hline $\begin{array}{l}\text { Jammu \& } \\
\text { Kashmir }\end{array}$ & 10.8 & 11.4 & 0.06 & 0.07 & 12,419 \\
\hline Jharkhand & 4.1 & 3.3 & 0.50 & 0.49 & 33,652 \\
\hline Karnataka & 20.3 & 26.1 & 1.23 & 1.15 & 62,374 \\
\hline Kerala & 7.0 & 11 & 0.94 & 0.07 & 35,677 \\
\hline $\begin{array}{l}\text { Madhya } \\
\text { Pradesh }\end{array}$ & 8.0 & 10.5 & 2.07 & 1.86 & 77,875 \\
\hline Maharashtra & 32.4 & 35.0 & 0.75 & 0.69 & 120,076 \\
\hline Manipur & 2.1 & 1.5 & 0.23 & 0.15 & 2,592 \\
\hline Meghalaya & 11.5 & 11.4 & 1.37 & 0.76 & 2,773 \\
\hline Mizoram & 10.3 & 8.7 & 2.16 & 2.82 & 1,063 \\
\hline Nagaland & 5.4 & 6.2 & 0.42 & 0.25 & 2,380 \\
\hline Odisha & 27.1 & 37.0 & 1.64 & 1.37 & 42,479 \\
\hline Punjab & 6.4 & 6.8 & 1.09 & 0.96 & 29,112 \\
\hline Rajasthan & 3.7 & 8.9 & 0.12 & 0.80 & 72,948 \\
\hline Sikkim & 15.3 & 14.4 & 0.46 & 0.31 & 647 \\
\hline Tamil Nadu & 36.6 & 36.4 & 0.91 & 1.24 & 69,396 \\
\hline Telangana & 23 & 30.6 & 0.56 & 0.75 & 35,193 \\
\hline Tripura & 12.4 & 13 & 0.26 & 0.21 & 3,826 \\
\hline Uttar Pradesh & 5.2 & 5.7 & 0.17 & 0.18 & 218,088 \\
\hline Uttarakhand & 4.4 & 4.0 & 0.24 & 0.21 & 10,632 \\
\hline West Bengal & 36.6 & 39.4 & 1.20 & 0.97 & 93,550 \\
\hline $\begin{array}{c}\text { Andaman \& } \\
\text { Nicobar } \\
\text { Islands }\end{array}$ & 22.9 & 28.3 & 0.36 & 0.36 & 551 \\
\hline Chandigarh & 7.8 & 8.7 & 0.84 & 0.56 & 1,780 \\
\hline $\begin{array}{c}\text { Dadra \& Nagar } \\
\text { Haveli }\end{array}$ & 153.3 & 164.2 & 2.61 & 0.71 & 422 \\
\hline Daman \& Diu & 40.6 & 32.4 & 0.00 & 0.30 & 330 \\
\hline Delhi & 1.0 & 1.8 & 0.17 & 0.06 & 21,285 \\
\hline Lakshadweep & 0.0 & 0.0 & 1.23 & 0.00 & 81 \\
\hline Puducherry & 51.5 & 64.5 & 0.48 & 0.54 & 1,669 \\
\hline Total & 15.8 & 18.2 & 0.72 & 0.70 & $1,268,960$ \\
\hline
\end{tabular}

Source - Authors have compiled this table analyzing the HMIS data.

a Estimation is based on state-wise projected population 2001-2026 (Registrar General-2006).

b Deaths due to Animal bites and Stings.

Maharashtra (35.0 persons). Similarly, the UTs of India show an increasing trend of reporting snakebites cases except Daman and Diu which has reported less numbers of people with snakebite compared to the year 2017-18. Surprisingly, Goa, West Bengal, Maharashtra and Andhra Pradesh reporting lower deaths despite having the higher cases registered with the snakebites in respective years.

\subsection{Mortality due to animal bites and stings}

The results of mortality due to animal bites and stings show that around 9,200 persons are died due to the animal bites and stings in the year 2017-18 in India (Table 1). Subsequently, there is decrease in the deaths due to the animal bites and stings in 2018-19 year but still it is 8,890 persons at the national level. State level analysis suggests that 


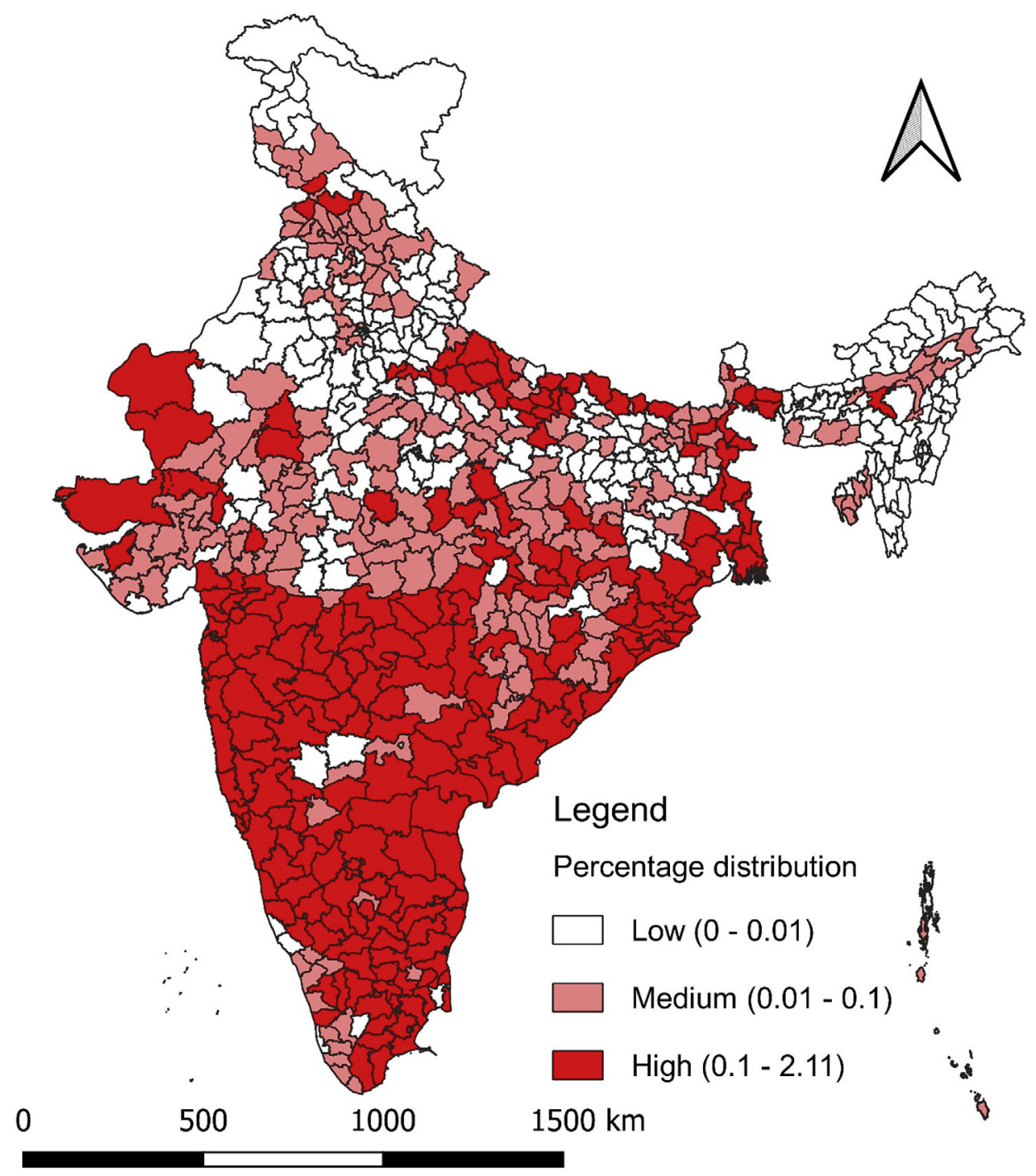

Fig. 1. District wise prevalence of Snakebite in India 2017-18.

around 2 persons died per 100,000 populations in Mizoram due to animal bites and stings in the years 2017-18, followed by Mizoram, UT - Dadra and Nagar Haveli (3 persons), Madhya Pradesh (2 persons), Chhattisgarh (2 persons), Odisha (2 persons) and Himachal Pradesh (1 person).

\subsection{District level prevalence of snakebite}

The district level analysis shows that the prevalence of snakebite is mainly dominated in the districts located in the southern states of peninsular deccan plateau. Particularly, districts from Maharashtra (14 districts), West Bengal (12 districts), Andhra Pradesh (9 districts), Tamil Nadu (8 districts), Telangana (2 districts), Odisha (2 districts) and Uttar Pradesh (2 districts) reported higher cases of snakebites in India during both consecutive years (Figs. 1 and 2). Purba Medinipur district from West Bengal and Nashik from Maharashtra reported highest cases of snakebites (4,904 and 4,294 respectively) during 201819 in India. Districts like Palghar $(3,204)$, Thane $(2,655)$, Kolhapur $(2,298)$, Pune $(2,102)$, Ratnagiri $(1,994)$ and Jalgaon $(1,842)$ reported higher snakebites cases compared to other districts in Maharashtra during 2018-19. West Bengal is a state which reported second highest cases of snakebites in 2018-19, in particularly, Purba Bardhhaman $(4,119)$, Nadia $(3,025)$, Bankura $(2,912)$, Murshidabad $(2,514)$ and Hugli $(2,394)$ reported more cases in the state compared to other districts. Andhra Pradesh especially at East Godavari (2,612), Krishna $(2,367)$, Srikakulam $(2,212)$, West Godavari $(2,184)$, Vishakhapatnam $(1,836)$ and Chittoor $(1,479)$ reported higher cases in south India. In Tamil Nadu, Cuddalore $(2,598)$, Vellore $(2,454)$, Viluppuram $(2,005)$ and Kancheepuram $(1,965)$ reported higher snakebite cases. On the other hand, Palakkad $(1,300)$ from Kerala, Sitamarhi $(2,186)$ of Bihar, Bhadrak $(2,065)$ and Jajpur $(2,961)$ from Odisha and Uttar Pradesh's Sultanpur $(1,062)$ and Ambedkar Nagar $(1,065)$ reported higher cases of snakebites in respective states with compared to the other districts.

\section{Discussion}

Our study highlighted that 2,00,492 persons were envenomed because of the snakebite and it was increased to 2,30,950 persons in the respective years of 2017-18 and 2018-19 in India. The state level analysis show that 38,904 people in Maharashtra registered with snakebites followed by 34,239 in West Bengal, Tamil Nadu $(25,399)$, Andhra Pradesh $(16,853)$, Karnataka $(12,661)$, and Odisha $(11,511)$ in 2016-17. Subsequently, the snakebite cases are increased in Maharashtra (42,026), West Bengal $(36,858)$, Andhra Pradesh $(18,767)$, Karnataka $(16,279)$ and Odisha $(15,717)$ during 2018-19. Previous studies substantiate our findings that in India around 2,00,000 people are victims of snakebites and about $15,000-30,000$ cases prove to be fatal every year. ${ }^{18}$ At the same time, states including West Bengal, 


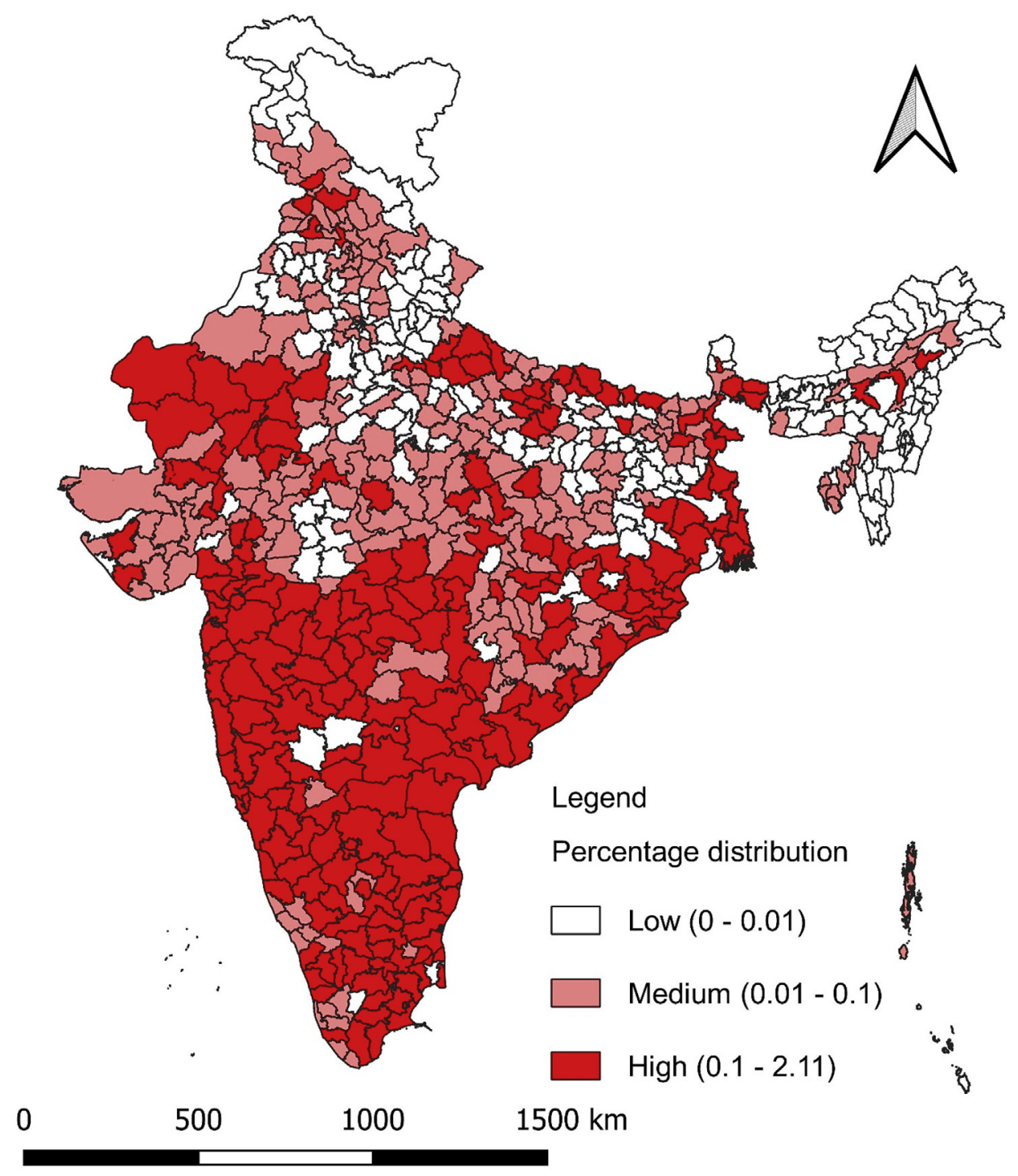

Fig. 2. District wise prevalence of Snakebite in India 2018-19.

Maharashtra, Tamil Nadu and Andhra Pradesh have higher contribution in order of reporting the snakebite cases. ${ }^{12,19,20}$ Out of 216 snake species in India, 52 are envenoms and may lead to the fatal outcomes. The commonly identified as "Big Four" snakes in India includes Indian cobra (Naja naja), Bungarus coeruleus (Krait), Russell's vipers and Sawscaled viper which frequently causes of lives of Indian. ${ }^{9,21,22}$ Close medical monitoring and early treatment interventions may save lives of many people associated with agriculture and living in rural parts of the country. ${ }^{21}$

Considering the districts among these higher reporting states, Maharashtra has 14 districts followed by West Bengal (12 districts), Andhra Pradesh (9 districts), Tamil Nadu (8 districts), and Telangana (2 districts) in India during two consecutive years. Districts like Purba Medinipur and Nashik has the highest registration of snakebite cases, this may determine to the geographical location and agriculture activities in respective areas. For instance, Purba Medinipur has lower IndoGangetic Plain and Eastern coastal plain and on the contrary Western Ghats stretches from north to south across the western portion of Nashik in Maharashtra. Nashik in other way is also dominated in the cash crop farming including the grape farming, sugar factories and wineries. This favorable natural and geographical conditions extend the survival of different species of snake in respective regions. Except the West Bengal, districts from southern states of peninsular deccan plateau dominated in India and registered higher prevalence of snakebite. Particularly, districts like Palghar, Thane, Kolhapur, Pune, Ratnagiri and Jalgaon of Maharashtra reported higher prevalence followed by East Godavari, Krishna, Srikakulam, West Godavari, Vishakhapatnam and Chittoor from Andhra Pradesh. Similarly, Cuddalore, Vellore, Viluppuram and Kancheepuram reported higher snakebite cases in Tamil Nadu. Considering the North Indian States, West Bengal has highest reported cases of snakebites including districts of Purba Bardhhaman, Nadia, Bankura, Murshidabad and Hugli. On the other hand, Palakkad, Sitamarhi, Bhadrak, Jajpur, Sultanpur and Ambedkar Nagar reported higher cases of snakebites when compared to other districts in India.

We extend our findings with highlighting the mortality due to the animal bites and stings in India. Our finding shows that around 9,200 persons died due to the animal bites and stings in India during the 2017-18. Subsequently there is a decrease in the deaths due to the animal bites and stings in 2018-19 year (8,890 persons). State level analysis suggests that Madhya Pradesh, Maharashtra, West Bengal, Andhra Pradesh, Karnataka, Tamil Nadu and Odisha registered higher deaths due to the animal bites and stings in India. The HMIS portal data do not clearly illustrated the snakebite as the cause of death. Therefore, it was difficult to attribute that the snakebite leads to death in India. In this regard, we have tried to establish the association between snakebite 


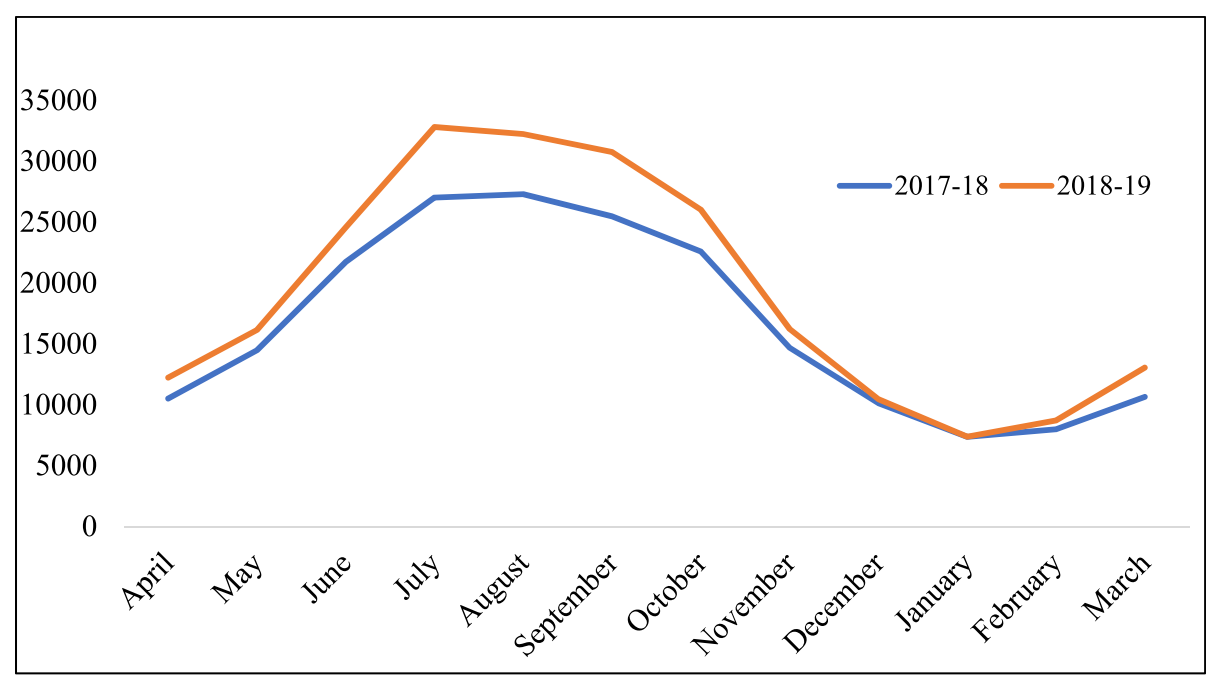

Fig. 3. Seasonal wise prevalence of snakebites in India.

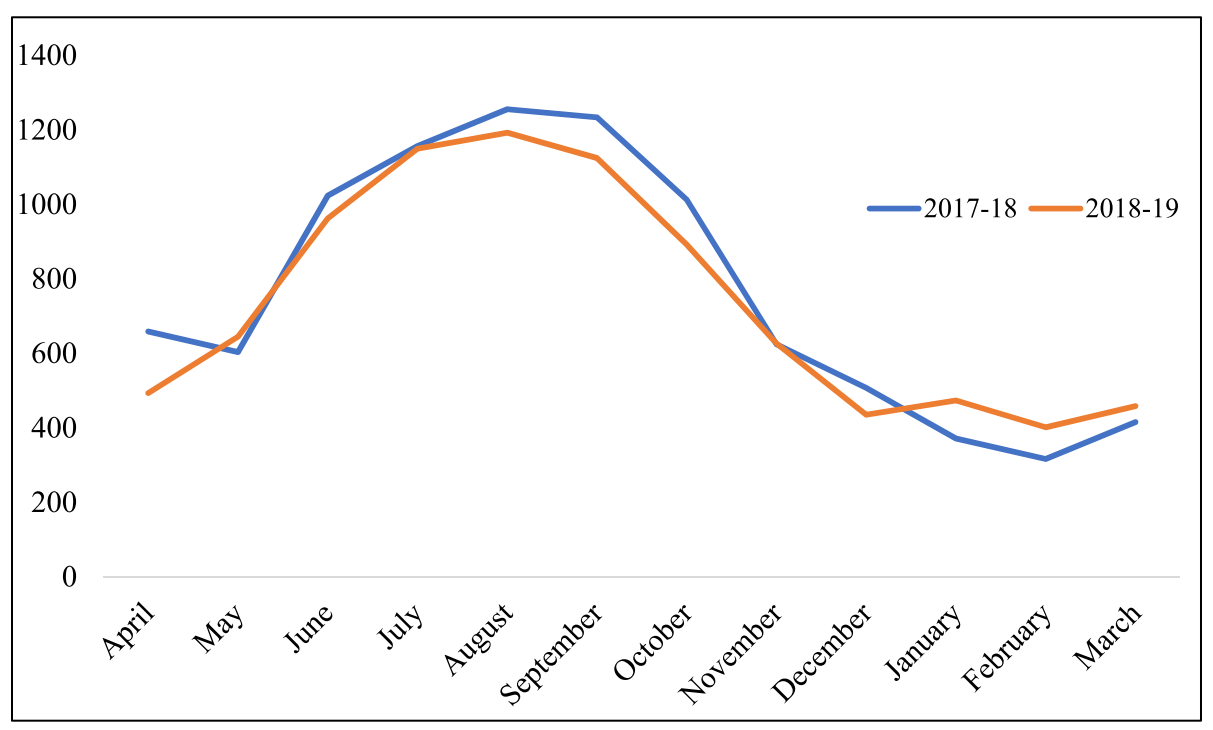

Fig. 4. Seasonal wise deaths due to animal bites and stings in India.

and mortality with illustrating the seasonal variation of deaths attributed to the animal bites and stings in India. Accordingly, we have plotted the seasonal variation in the prevalence of snakebites and associated deaths reported at the national level. Figs. 3 and 4, illustrate the possible association between snakebite and deaths due to animal bites and stings. Peculiarly, Fig. 3 shows that majority of people have snakebites during the months of May to November during both the years. This period mainly considered as the monsoon season in India. The prevalence may be high because of the rainy situation where people expose to the snakes in nearby community area. Further, Fig. 4 illustrated the seasonal wise deaths of people due to animal bites and stings in India. In respect to Figs. 3 and 4 has identical pattern of higher deaths due to the animal bites and stings during the months of May to November. With the limitations of deaths due to other reptiles' bite excluding the snakebite, we reinstate that the majority of these deaths are attributed to the envenoming of snakebite in India. The possibilities of over and under reporting of death due to the snakebites are inevitable in socioeconomically poor states including Bihar, Madhya Pradesh and Uttar Pradesh. For instance, a sample based study by Mohapatra (2011) estimated total 4,500 deaths due to the snakebite in Bihar whereas hospital based clinical study by Armstrong (2019) estimated 254 deaths in $2015 .^{10,23}$ In addition, our study show that 134 deaths were occurred in Bihar due to the animal bites and stings in 2018.

\subsection{Conclusion}

The morbidity and mortality due to envenoming of snakebite is preventable and avoidable with adequate medical intervention in developing countries. As suggested by previous studies snakebite envenoming must be treated as a major health issue which affects mainly the people with lower socioeconomic status, reside in remote and rural region of the country. ${ }^{1,24}$ In this respect, our study has several important findings with applicable limitations adhere to the data availability. We have first time estimated the prevalence of snakebite at the district and state level in India using the nationally representative data. This would significantly contribute to the policy making at all the administrative level including local governance, district, state level and eventually to the nation. In the larger perspective snakebite has remained an underestimated cause of accidental death in modern India which needs to be address through possible health policy. Our study, suggests that the cases of snakebite can be reduced considerably by taking proper precautions during the rainy season. Additionally, awareness of taking preventive and curative measures including 
wearing protective foot-wears, carrying a stick, approaching debris cautiously, paying attention to the ground during agricultural work are most effective tools that bring down the prevalence of snakebite. ${ }^{25}$ The availability of anti-snake venom at the primary health facility, emergency transport facility, correct first aid measures can bring down the fatal events due to the animal and snakebite in India.

\subsection{Limitations}

The study has few limitations including the data availability, we have used HMIS data which is available on snakebites reported by the government health facilities in India. The cases those were not registered and failed to report at the public health facilities were excluded from the analysis. Hence, the number of snakebite reported cases in public health facilities may be less than the actual number of cases occurred in the country. In the large context, the data from the private health facilities is not available in the country. The completeness of HIMS data reporting is subjective to the level of district development in India. ${ }^{16,26}$

\section{Availability of data and materials}

The data used for the study is obtained from the web portal of Health Management Information System. No separate ethics statement and consent for publication was required for this study as the HMIS collect the secondary data from the health facilities of India.

\section{Funding}

No funding for this study.

\section{Informed consent}

Not applicable.

\section{Authors contributions}

(1) Dr. Salve has conceptualized and designed the study. (2) Mr. Vatavati analysed the data and interpreted the result of analysis . (1) Dr. Salve drafted the article and revised it critically for important intellectual content. (3) Professor Hallad finalized and approved the article version to be submitted.

\section{Declaration of competing interest}

None.

\section{Acknowledgements}

No applicable.

\section{References}

1. The Lancet. Snake-bite envenoming: a priority neglected tropical disease. Lancet 2017;390(10089):2. https://doi.org/10.1016/S0140-6736(17)31751-8.

2. WHO. Snakebite envenoming. World health organisation. Published https://www who.int/news-room/fact-sheets/detail/snakebite-envenoming; 2019, Accessed date: 28 June 2019.

3. Sharma N, Chauhan S, Faruqi S, Bhat P, Varma S. Snake envenomation in a North Indian hospital. Emerg Med J. 2005;22:118-120. https://doi.org/10.1136/emj.2003. 008458.

4. Snakebite Envenoming WHO. A Strategy for Prevention and Control. Geneva: World Health Organization; 2019https://apps.who.int/iris/bitstream/handle/10665/ 324838/9789241515641-eng.pdf.

5. Sharma SK, Koirala S, Dahal G, Sah C. Clinico-epidemiological features of snakebite: a study from Eastern Nepal. Trop Doct. 2004;34(1):20-22. https://doi.org/10.1177/ 004947550403400108

6. Longkumer T, Armstrong LJ, Finny P. Outcome determinants of snakebites in North Bihar, India: a prospective hospital based study. J Venom Res. 2017;8:14-18https:// www.ncbi.nlm.nih.gov/pubmed/29285350.

7. Kasturiratne A, Wickremasinghe AR, de Silva N, et al. The global burden of snakebite: a literature analysis and modelling based on regional estimates of envenoming and deaths. PLoS Med. 2008;5(11):e218. https://doi.org/10.1371/journal.pmed. 0050218.

8. Pandey K. Half the global snake bite deaths happen in India. Why are we not prepared? Down To Earth. Published https://www.downtoearth.org.in/news/wildlifebiodiversity/serpentine-problem-58396; 2017, Accessed date: 20 June 2019.

9. Whitaker R. Snakebite in India today. Neurol India. 2015;63(3):300-303. https://doi. org/10.4103/0028-3886.158155.

10. Mohapatra B, Warrell DA, Suraweera W, et al. Snakebite mortality in India: a nationally representative mortality survey. PLoS Neglected Trop Dis. 2011;5(4):e1018https://doi.org/10.1371/journal.pntd.0001018.

11. Alirol E, Sharma SK, Bawaskar HS, Kuch U, Chappuis F. Snake bite in south Asia: a review. PLoS Neglected Trop Dis. 2010;4(1):e603. https://doi.org/10.1371/journal. pntd.0000603.

12. Ghosh R, Mana K, Gantait K, Sarkhel S. A retrospective study of clinico-epidemiological profile of snakebite related deaths at a Tertiary care hospital in Midnapore, West Bengal, India. Toxicol Rep. 2017;5:1-5. https://doi.org/10.1016/j.toxrep.2017. 11.008 .

13. Dandona R, Kumar GA, Kharyal A, George S, Akbar M, Dandona L. Mortality due to snakebite and other venomous animals in the Indian state of Bihar: findings from a representative mortality study. PloS One. 2018;13(6):e0198900https://doi.org/10. 1371/journal.pone.0198900.

14. Paul V, Pratibha S, Prahlad KA, Earali J, Francis S, Lewis F. High-dose anti-snake venom versus low-dose anti-snake venom in the treatment of poisonous snake bites-a critical study. J Assoc Phys India. 2004;52:14-17.

15. Narvencar K. Correlation between timing of ASV administration and complications in snake bites. J Assoc Phys India. 2006;54:717-719.

16. Pandey A, Roy N, Bhawsar R, Mishra RM. Health information system in India: issues of data availability and quality. Demogr India. 2010;39(1):111-128https://www. researchgate.net/publication/232084914.

17. General Registrar, Commissioner Census. Population Projections for India and States 2001-2026, Report of the Technical Group on Population Projections Constituted by the National Commission on Population 2006; 2006 New Delhi.

18. Swaroop S, Grab B. Snakebite mortality in the world. Bull World Health Organ. 1954;10(1):35-76https://www.ncbi.nlm.nih.gov/pubmed/13150169.

19. Bhattacharyya $P$, Chakraborty A. Neurotoxic snake bite with respiratory failure. Indian J Crit Care Med. 2007;11. https://doi.org/10.4103/0972-5229.35627.

20. Punde D. Management of snake-bite in rural Maharashtra: a 10-year experience. Natl Med J India. 2005;18(2):1-5https://www.ncbi.nlm.nih.gov/pubmed/15981441.

21. Bawaskar HS, Bawaskar PH. Snakebite envenoming. Lancet. 2019;393(10167):131. https://doi.org/10.1016/S0140-6736(18)32745-4.

22. World Health Organization. Guidelines for the Management of Snakebites. second ed. 2016; 2016 New Delhi.

23. Armstrong LJ, Cynthia S, George M, Zachariah A. Comparing community and hospital data of snakebite in North Bihar: a community incidence survey and a parallel hospital-based clinical study. Trop Doct. July 2019:0049475519865036https://doi. org $/ 10.1177 / 0049475519865036$.

24. Longbottom J, Shearer FM, Devine M, et al. Vulnerability to snakebite envenoming: a global mapping of hotspots. Lancet. 2018;392(10148):673-684. https://doi.org/10. 1016/S0140-6736(18)31224-8.

25. Anjum A, Husain M, Hanif S, Sm A, M B, et al. Epidemiological profile of snake bite at tertiary care hospital, north India. Forensic Res. 2012;3(146) https://doi.org/10. 4172/2157-7145.1000146.

26. Sharma A, Rana SK, Prinja S, Kumar R. Quality of health management information system for maternal \& Child health care in Haryana state, India. PloS One. 2016;11(2):e0148449https://doi.org/10.1371/journal.pone.0148449. 